\title{
Necesidad del Centro de Documentación Fotográfica Nacional en España
}

\author{
Juan Miguel Sánchez Vigil \\ Belén Fernández Fuentes \\ Juan Carlos Marcos Recio \\ Universidad Complutense de Madrid (España)
}

\section{Resumen}

Se pretende demostrar la necesidad de la creación de un centro de documentación fotográfica a nivel nacional en el que se incluya (para su organización y conservación) toda documentación de este tipo existente y dispersa en diversas instituciones. Para ello se estudiarán los archivos fotográficos ya conocidos y organizados, sus fondos y sus modos de trabajo, así como las instituciones que generen o conserven documentos fotográficos. Así mismo se estudia la fotografía como documento, con el fin de justificar la necesidad de conservación de estos materiales.

Palabras claves: Centro Nacional de Documentación Fotográfica Documentación fotográfica. Fotografia.

\section{Abstract}

The need for creating a Spanish National Centre for Photographic Documentation is addressed. Its aims should be to coordinate the different existing centres, promote their development and spread the knowledge of their holdings. The value of photographic documents since their invention in 1839 is also stressed, and, from this point, the process of preserving, organizing and disseminating them is carefuly presented.

Keywords: National Centre for Photographic Documentation. Public and Private. Documentation Centres. Photographic documentation. Photography.

\section{La fotografía como documento}

Desde el punto de vista científico, documentación fotográfica es la ciencia que tiene por objeto el estudio del proceso de comunicación de las fuentes fotográficas para la obtención de nuevos conocimientos aplicados a la investigación y al trabajo fotográfico. Con carácter general definimos documentación fotográfica como 
"Documento o conjunto de documentos cuyo soporte es la fotografía en cualquiera de sus aspectos técnicos: negativo, positivo, diapositiva, fichero digital, etc.”. Joan Costa distingue tres modelos fotográficos: documento, arte y lenguaje. Define el primero como aquel en el que predomina el objeto real, en el segundo destaca la originalidad (actitud creativa) y en el tercero la componente técnica (actitud experimental). El historiador Lee Fontanella (1992, p. 25) identifica la foto documento con las escenas cotidianas, con las imágenes que vivimos a diario en la intrahistoria particular. Tal situación no es definitiva, puesto que los referentes pueden perderse en determinados casos, siempre vinculados a la voluntad del autor, a la creación, a la forma de mirar o de captar las parcelas de la mirada:

La fotografía documental suele tener un referente de fácil reconocimiento en el mundo real, por lo menos en el momento en que aquella se realiza. Pero podemos perder el sentido de ese referente de varios modos y por varias razones. Una de estas se encuentra en la afirmación hecha por Hartman, al efecto de que el medio de difusión del documentalismo tiende a ser proporcionalmente menos documentalista al incluirse hacia el estilo pictorialista.

Profesionales, investigadores e historiadores establecen similitudes y diferencias entre fotografía documental y artística, olvidando que aunque no se pretenda informar cualquier imagen ofrece mensajes a través de su lenguaje específico y por consiguiente puede ser decodificada por el receptor. De la relación entre arte y documento ha escrito Rosa Olivares (2003, p. 15):

Aunque personalmente considere que "documento" es algo que realmente se puede adjudicar a cualquier fotografía - como a prácticamente cualquier obra de arte-, pues documento de una época y de una forma de mirar y de analizar es el arte, y siempre lo ha sido desde el origen del hombre, desde el arte más primitivo. De hecho, el concepto arte es una creación muy posterior al objeto que define, y "artista" como tal no existe hasta el siglo XVI con León Batista Alberti, que aboga por el paso de artesano a artista.

Man Ray aseguró que la fotografía no era artística basándose en la cualidad de medio rápido contrapuesto a la lentitud de la pintura, lo que significa que solo es artístico aquello en lo que se invierte "determinado tiempo". Alfred Stieglitz unió arte y documento al afirmar que buscaba en sus fotografías la belleza y la verdad, y Susan Sontag (1996, p. 185) funde ambos aspectos en el propio significado de la fotografía:

Para nosotros la diferencia entre el fotógrafo como mirada individual y el fotógrafo como cronista objetivo parece fundamental, y con frecuencia esa diferencia se considera erróneamente la frontera entre la fotografía como arte y la fotografía como documento. Pero ambas son extensiones lógicas de lo que significa la fotografía: la notación, potencialmente, de cuanto hay en el mundo desde todos los ángulos posibles.

Andreas Feininger (1977, p. 45) diferencia la fotografía por su tratamiento, bien sea ilustrativo o interpretativo. Identifica el primero con un planteamiento 
próximo a la realidad, mientras que considera el segundo como una actitud subjetiva, donde la simbología cobra el máximo interés frente al objeto fotografiado:

Mientras la fotografía documental se ocupa principalmente de temas, hechos y acontecimientos específicos, la fotografía creadora se interesa por la esencia de las cosas y de su interpretación. En este tipo de fotografía el tema se convierte en el vehículo de expresión de una idea, un símbolo que representa algo más que la simple y escueta reproducción de su imagen.

Henry Matisse afirmó que la fotografía podía aportar los documentos más valiosos y al tiempo ser presentada como arte si el autor era un hombre de buen gusto, y Joan Fontcuberta sigue esta consideración matizando que el documentalismo logró hegemonizar la fotografía en los años setenta entre aquellos que la utilizaban como medio creativo. Santiago Trancón Pérez (1986, p. 11) vincula el documento al "símbolo del instante y la vida" y lo presenta como imprescindible en la recuperación del pasado:

El proceso de destrucción y sustitución de muchos conocimientos, usos y costumbres de nuestra cultura tradicional por elementos culturales ajenos pone en peligro un legado valiosísimo sin que ello suponga una mejora de nuestras relaciones sociales ni de nuestro bienestar... Nada más útil que la fotografía, por tanto, para reflexionar sobre nuestro pasado, sobre los cambios sociales y culturales ocurridos en nuestra sociedad.

La fotografía es un elemento comunicativo cuyas características se determinan en su propio desarrollo. Paul Strand la definió en la revista Camera Work de diciembre de 1917 como "La primera y única contribución de la ciencia al arte que encuentra su razón de ser, como cualquier medio, en una completa unicidad de intenciones; es decir, en una absoluta e incalificable objetividad". Las definiciones en diccionarios y enciclopedias coinciden salvo en leves matices, y como ha indicado Veit Gorner desde que el medio fotográfico se ha digitalizado es imposible dar una definición exacta del término:

Según Susan Sontag: "Una fotografía no es solo una imagen (en el sentido en que lo es una pintura), una interpretación de lo real; también es un vestigio, un rastro directo de lo real, como una huella o una máscara mortuoria". La foto se compone de continente y contenido, el primero materializado en soporte y el segundo plasmado en la representación visual; por otra parte, es necesario un autor que, utilizando los medios adecuados (tecnología), haga realidad esa imagen. En última escala aparecen otros dos elementos: el receptor, que puede ser el mismo autor, o bien otro personaje (familia, amigos, interesados, cliente, público, investigador, etc.), y un medio de comunicación encargado de la difusión o conservación (prensa, editorial, audiovisual, etc.). Todos estos elementos conforman un esquema que hace del proceso fotográfico un proceso comunicativo estudiado desde tantos aspectos como posibilidades de aplicación.

En todo acto fotográfico el autor selecciona el fragmento a fotografiar y construye un mensaje (contenido) dirigido a un receptor que puede utilizarlo como 
desee. El resultado final es el documento fotográfico (mensaje en un soporte). $\mathrm{Si}$ el documento es la combinación de un soporte y la información registrada en él, el documento fotográfico es aquel que representa la información en un soporte fotográfico analógico o digital. Todo mensaje puede contemplarse desde tres aspectos: sujeto, objeto y medio, que conforman un triángulo escaleno variable según el valor de cada uno. Joan Costa (1997, p. 29) establece una escala de motivaciones del público frente al documento fotográfico, desde la más absoluta indiferencia hasta lo que denomina "pasión creativa", que desarrolla en cinco niveles: Imagen prefabricada (fotografía impresa), fototurismo (foto de recuerdo), imitación o motivación sentimental (foto de aficionado), reproducción o testimonio (fotografía documental) e independencia progresiva (fotografía experimental). Todos estos modelos tienen un denominador común: su valor documental.

Roland Barthes (1994, p. 140) indica que la fotografía nació históricamente como arte de la persona, como representación de lo que denomina "la reserva del cuerpo". Como tal representación alcanza el valor de documento, y ello con independencia del autor de la misma. Generalmente se tiende a valorar el documento considerando el nombre del autor, si bien las imágenes personales (ingenuas, comerciales, particulares, utilitarias, de recuerdo, etc.) no se diferencian en muchos casos de las excepcionales tomas de los "maestros". Hay imágenes de aficionados, frente a las de profesionales, que sorprenden al receptor por sus complejos y representativos contenidos.

El documento fotográfico tiene dos lecturas primarias: su representación original a partir de la selección de la realidad, es decir, lo que se pretende captar para crear, comunicar o informar de o sobre algo, y en segundo lugar lo que sugiere al receptor. La interpretación de la imagen puede variar la intención primaria e incluso sugerir tantas ideas como miradas. Cualquier fotografía de moda captada con intención de vender un producto debe transmitir el mensaje publicitario, pero también ofrece el retrato del personaje (masculino o femenino), que puede producir rechazo o atracción en función de la cultura del receptor, e incluso nos ofrecerá un entorno, decorado o ambiente que nos informa de dónde, cuándo y cómo fue realizada, cuestiones que condicionan y matizan ideas. Apliquemos estas reglas a las instantáneas deportivas, taurinas, de guerra, sucesos, etc., y justificaremos los valores del documento fotográfico. Por consiguiente, el documentalista deberá analizar la fotografía con criterios universales, sin límites interpretativos, para extraer la mayor información.

W. M. Ivins establece un código lingüístico que define la fotografía artística como expresión visual y la documental como información visual, y Jean A. Keim identifica el documento con la fotografía fiel, con el testimonio, y pone como ejemplo los hechos relevantes de la historia mundial, incluidas las guerras. Philippe Dubois señala tres consideraciones en cuanto al valor documental de la 
imagen fotográfica: en primer lugar la verosimilitud, entendida como la reproducción mimética de lo real; en segundo témino la simbología, imagen analizada como interpretación y/o transformación de la realidad, como creación arbitraria, cultural, ideológica y perceptualmente codificada; y, por último, como índice donde la imagen queda vinculada inseparablemente a su referente.

La historia del documento fotográfico está vinculada a la propia historia de la fotografía. En el libro The Pencil of Nature (1844-1846), Henry Fox Talbot (1997, p. 45) explica sus experimentos para fijar la imagen, pero también su obsesión por representar los objetos, los paisajes, las formas y las personas. Las láminas originales de la edición fueron descritas con la pretensión de dejar constancia de los hechos; así, sobre la simple reproducción de varios objetos de porcelana en una vitrina, escribió:

Los objetos representados en esta ilustración son numerosos. Pero por numerosos que sean, por complicado que sea su arreglo, la cámara representa todos a la vez. Se puede decir que realiza una imagen de lo que ve. El objetivo es el ojo del instrumento y el papel sensitivo se puede comparar con la retina.

En el documento fotográfico, los contenidos vienen dados por la representación de la imagen. El valor es subjetivo en el encuadre, pero la realidad pertenece al mundo de los demás. Únicamente puede seleccionarse el espacio, mientras que la luz es ambiental, salvo que intervengan factores externos, en cuyo caso entramos en el campo creativo. La lectura del documento permite un completo análisis técnico y de contenidos, desde el formato hasta los detalles más reservados del encuadre. No obstante, la diferencia debe establecerse desde los contenidos, toda vez que nos propongamos un análisis exhaustivo del documento.

La consideración de la fotografía como arte nos lleva al fenómeno que denominamos el arte a través del arte, cuando su función es captar objetos o escenas artísticas. Es el caso de la reproducción de pinturas, esculturas, grabados y otros elementos artísticos, y también tomas que se corresponden con expresiones artísticas: arquitectura, danza, música, etc. Se produce aquí la máxima aproximación a la fotografía como arte, puesto que en el proceso de creación el contenido presenta ya valores artísticos.

Los primeros trabajos de Blanquart-Evrard en lo que a edición fotográfica se refiere contemplaban la reproducción de las obras de arte en conjunto y detalle, ya que mostraban los secretos del pasado (arqueología) y los aspectos ocultos a los que el público en general no podía acceder (colecciones privadas). Ernest Lacan lo describió el 9 de abril de 1853 en La Lumière:

En las más altas cornisas de las catedrales, en las galerías en donde la golondrina y el cuervo hacen su nido, hay figuras de santos o vírgenes que ningún ojo humano ha podido contemplar jamás de cerca y que el objetivo descubre y reproduce con toda la suavidad de sus formas y actitud.

Scire. $11: 1$ (en.-jun. 2005) 159-173. ISSN 1135-3761. 
Charles Blanc escribió en la Gazette des Beaux-Arts (1860) que el mejor y más noble uso que podía hacerse de la fotografía consistía en reproducir grandes obras de arte. El francés Jean Laurent, establecido en España desde mediados del siglo XIX, tuvo como especialidad entre sus múltiples facetas la reproducción de obras de arte y editó varios catálogos comerciales con detalle de los fondos y los precios por copia. En el Catalogue des principaux tableaux des musées d'Espagne, editado en 1868, leemos:

Hoy, cuando los entendidos se han habituado a ver los cuadros originales en las fotografías como a través de un espejo, y que sus ojos, familiarizados con la nueva gama del arte que nosotros profesamos, gozan de la contemplación del original del mismo, no podemos temer que esta segunda serie de reproducciones tenga una acogida menor que la que tuvo la primera.

Al receptor, documentalista o usuario, no le basta con saber que existen documentos, ni siquiera le es suficiente que con la noticia se facilite un resumen del contenido de los mismos, sino que necesita disponer de ellos. Los documentos fotográficos conservados en las fototecas son originales o reproducciones, mientras que aquellos que aparecen en cualquier tipo de publicación son siempre reproducción de otros documentos (textos, dibujos, cuadros o las propias fotografías). Con la expresión fotografía original nos referimos a las tomas de aquellos hechos noticiables, ambientes, retratos y paisajes en sentido general en un momento irrepetible (instante definido por un tiempo y espacio concretos) y que por tanto no puede ser recreado. La reproducción fotográfica es la copia en el sentido global de esta palabra. Un cuadro, una escultura, la página de un libro, un manuscrito o una fotografía original pueden reproducirse con el mismo resultado: negativo, positivo o fichero digital. Desde esta perspectiva, el documento fotográfico va más allá de la simple fotografía en cuanto que contiene información. Establecemos así dos niveles, uno creativo o idea nueva (originalidad), que se refiere a la toma o captación directa de la imagen del objeto, sujeto, motivo o paisaje; y otro recreativo o reprográfico (copia del original), que permite la transmisión del mensaje mediante fiel reproducción.

La función reprográfica de la fotografía ha hecho - hace - posible la popularización, el conocimiento de los contenidos conservados en museos públicos y privados. Considerados como centros de documentación, sus fondos se popularizaron (multiplicidad de la imagen) para cubrir una función social importante. La reproducción de objetos fue una de las primeras intenciones de Nicéphore Niepce, mientras que Henri Fox Talbot reprodujo por primera vez en 1844 en Pencil of Nature la página de un impreso de su biblioteca. En España, las reproducciones artísticas fueron pensadas como documento y como negocio: Charles Clifford reprodujo las piezas de la Armería de Palacio por encargo de la Casa 
Real, mientras que Jean Laurent fotografió los cuadros del Museo del Prado con el fin de incluirlos en su catálogo de obras de arte.

Fuera de España, la reproducción de obras de arte dio lugar a la creación de galerías tan prestigiosas como la italiana Alinari, fundada en Florencia en 1850 (hoy en activo) con el fin de reunir documentos fotográficos de las obras de arte de aquella ciudad. El ámbito geográfico fue ampliado después a toda Italia y llegó a almacenar la colección de fotografías más importante de Europa. A los fondos de Alinari recurrieron las editoriales francesas, alemanas, italianas y españolas que pretendieron a principios del siglo XX recopilar el saber universal en las enciclopedias; hasta entonces las obras de arte eran campo limitado para unos cuantos privilegiados, pero en muy poco tiempo fueron puestas a disposición de las masas. En Francia, Adolphe Braun comenzó en 1862 la reproducción metódica de pinturas y dibujos en los museos de Basilea, Milán, Florencia, Venecia o Dresde, y cinco años después tenía empleados a cien obreros y la reproducción de obras de arte era ya industria.

Otra función documental fue la identificativa. La tarjeta de identidad es testimonio de la existencia, testigo fiel de la personalidad intercambiable, referencia al pronombre. Ninguno de los datos textuales tiene valor si el retrato del individuo no los refrenda. Así ocurre con gran cantidad de documentos de carácter particular o general, internos y externos, nacionales e internacionales, cuya función depende de la fotografía: pasaportes, carnés de conducir, prensa y estudio, fichas deportivas, etc.

Como documento científico, la fotografía participa de las mismas notas de información y de fuente informativa, y se integra en el proceso informativo-documental: emisor (autor), canal o medio de transmisión (soporte), y receptor o usuario del mensaje (documento). Se convierte así en documento en cuanto que nos informa acerca de algo, puede ser interpretada a través del análisis y es reproducible; es decir, que puede o debe ser reproducida para su difusión. Susan Sontag (1996, p. 69) escribió que algunos fotógrafos se convierten en científicos mientras que otros tratan los temas más delicados convirtiéndose en moralistas, e identifica a los científicos con los documentalistas en cuanto que "hacen un inventario del mundo". En la fotografía siempre hay alguien o algo que algún día dejará de ser, que desaparecerá sin dejar más huella que su imagen. En el momento en que leemos estas páginas, miles de objetos, personas, paisajes, situaciones dejan de ser o existir para formar parte del documento fotográfico. Por ello la definición de fotografía documental se ha realizado por exclusión y se considera documental lo que no es artístico o creativo. El término es tan genérico que incluye numerosos géneros o especialidades: reportaje, moda, retrato, etc. La cantidad y la calidad de los contenidos determinarán su fuerza, riqueza e importancia. 


\section{Los centros de documentación}

La fotografía ha estado - está - presente en cualquier actividad social, de ahí que aparezca con entidad propia o vinculada a otros documentos en cualquier institución o empresa. Los documentos fotográficos se hallan dispersos en álbumes, colecciones, fototecas, archivos o museos; encontramos conjuntos documentales de excepcional valor histórico, informativo y artístico. Por ello se han creado centros dedicados a su recopilación, conservación, análisis o difusión, con fines lucrativos o no. Apoyar las actividades de todos estos centros en la primera tarea de recuperación es un fin del profesional, investigador, científico o aficionado. Gran parte de estos centros no difunden los fondos y tampoco realizan el complejo proceso de la cadena documental, ya que la simple labor de adquisición es a veces tan dificultosa como vital para la conservación de las colecciones.

Los historiadores han realizado una importante labor divulgativa y, actualmente, las fotografías no solo son valoradas, sino codiciadas por los responsables de los centros de documentación, tanto por su contenido como por su continente. $\mathrm{Al}$ investigar sobre estos centros, encontramos dos vías diferenciadas en cuanto a su gestión y administración: fondos conservados en organismos oficiales controlados por los poderes públicos, y empresas cuyo negocio consiste en ofrecer al usuario un servicio de alquiler y cesión de tales documentos. La recuperación y catalogación les corresponde a ambos: organismos públicos y empresas privadas, y las funciones de cada uno de ellos se contemplan desde dos puntos de vista. Los organismos públicos: preservar - conservación de los documentos-, documentar - proceso documental - y difundir - dar a conocer los documentos-. Las entidades privadas: preservar y documentar, promocionar - publicación, marketing, publicidad, etc. - y rentabilizar - desarrollo empresarial.

Montserrat Bailac y Montserrat Català (1995, p. 162) distinguen entre fototecas comerciales y no comerciales, en función de que obtengan ingresos propios o bien dependan de los presupuestos de una institución o de fondos públicos. Para María Eulalia Fuentes i Pujol (1995, p. 139) los centros de documentación son aspecto clave en el proceso de información:

Los archivos de imágenes, archivos de fotografías o fototecas y de ilustraciones de prensa, las filmotecas, videotecas y fonotecas, forman una parte importante de la información periodística y, por tanto, son imprescindibles en cualquier planteamiento documental de los servicios de documentación de los distintos medios de comunicación de masas.

\subsection{Instituciones públicas}

Los centros públicos realizan actividades específicas y su función, en la mayoría de los casos, no tiene relación con la fotografía, si bien para su tratamiento se han creado departamentos especiales. La recuperación de obras de 
autores olvidados y/o ignorados ha contribuido a la creación de nuevos archivos y fototecas en ayuntamientos, diputaciones y comunidades. Valorando en su justa medida la función que desarrollan los profesionales en estas instituciones, se hace necesario el control de los fondos fotográficos desde una oficina especializada que recoja información de los fondos privados, base del conjunto documental en los actuales archivos públicos. Establecemos una tipología referencial de centros públicos como punto de partida: archivos, bibliotecas y hemerotecas, institutos y fundaciones, museos y otras instituciones - universidades, filmotecas, academias, consejerías, etc.

Cada uno de estos sectores incluye instituciones que conservan extraordinarios fondos (Archivo General de la Administración del Estado, Instituto del Patrimonio Histórico, Biblioteca Nacional, Museo Reina Sofía, Instituto Valenciano de Arte Moderno, etc.). Además de las instituciones documentales al uso, hay otros centros encargados de la custodia, tratamiento y difusión de fondos, algunos creados para la salvaguarda del patrimonio fotográfico como el Centro Galego de Artes da Imaxe o el Centre de Recerca i Difusió de la Imatge. Hay también organismos autónomos con más de una función; es decir, que realizan tareas de bibliotecas, museos, fototecas, etc. Por otra parte, la creación de colecciones de arte fotográfico dependientes de las Consejerías de Cultura de las Comunidades Autónomas ha generado fondos extraordinarios como el de la Comunidad de Madrid, cuya pretensión es promocionar nuevos autores.

Félix del Valle (1990, p. 210) establece la tipología de centros y servicios de documentación a partir de las mediatecas, definidas como "Centros cuyo objetivo es la conservación y difusión de documentos audiovisuales. Dentro de estos están las fototecas (fotografías), filmotecas (películas), videotecas (vídeo) y fonotecas (discos y cintas). Por la peculiaridad de sus soportes suelen tener condiciones especiales de difusión, siendo generalmente bastante restrictivas".

La labor del profesional de la fotografía, en su faceta de documentalista, une dos actividades que no siempre se cumplen. Por un lado, la toma de la imagen y, por otro, su posterior catalogación y documentación. Pocos son los profesionales que realizan esta tarea, por lo que la recuperación de las obras ha sido - es - muy complicada ante la falta de datos. Estos archivos personales y las colecciones de autor han dado origen a centros públicos. La organización de estos modelos es fundamental para rentabilizar los fondos y requiere un sistema de trabajo y una dedicación metódica. Alfonso Sánchez Portela (Alfonso) vivió durante los años ochenta y noventa de la explotación de su archivo histórico, hoy conservado en el Archivo General de la Administración de Estado, y Xavier Miserachs (1995, p. 172) confesó que al desbordarle el material de su archivo decidió entregarlo a una empresa especializada para su informatización y gestión, pero esto no es lo habitual y el tratamiento de estos fondos requiere de mucho tiempo.

Scire. $11: 1$ (en.-jun. 2005) 159-173. ISSN 1135-3761. 
Los fondos rescatados presentan, en general, una desorganización absoluta, teniendo por norma la agrupación de temas o retratos de personajes, lo que al menos permite un punto de partida. El desorden ha sido la causa primera de que herederos o responsables de la obra hayan decidido en muchos casos su destrucción sin el menor escrúpulo. Las excepciones han permitido una labor documental que pretende poner a disposición del usuario la información contenida en las fotografías y las copias positivas a partir de los originales. Así los archivos de Laurent y Moreno (Instituto del Patrimonio Histórico), Alfonso (Archivo General de la Administración) y Kaulak (Biblioteca Nacional), fundamentales por la calidad y cantidad de su obra, tratada en publicaciones específicas. En este sentido, como ya hemos comentado, los trabajos de historiadores han sido claves al editar catálogos y divulgar sus investigaciones.

El tratamiento documental de las fotografías difiere en función de su aplicación. La diversidad de objetivos implica distintas metodologías en la elaboración de bases de datos, si bien el criterio debe ser el más amplio posible a partir del análisis previo. Coincidimos en esta valoración con Bailac y Català (1995, p. 164 ), puesto que «Una fototeca de prensa forzosamente sería diferente del fondo fotográfico de la Biblioteca Nacional o de un centro empresarial". Las fototecas particulares crean las bases de datos en función del peticionario, a veces con estructuras simples y otras con tratamiento informático que incluye marcas de agua en las digitales y códigos de barras en los protectores y dorsos de las diapositivas. En los centros oficiales se cataloga siguiendo las reglas para materiales especiales, pero estas normas son modificadas (ampliadas o reducidas) en los archivos privados.

De modo genérico hay que distinguir entre continente (soporte y características técnicas) y contenido (descripción de la imagen). De una parte interesan los datos referenciales: autor, fecha, tipo y modelo de película, formato, etc., y de otra los descriptores: tema, materia, localización, etc. Conviene insistir en que la prioridad dependerá de la especialidad de la fototeca y el punto de partida está en la adquisición de fondos, que tiene varias vías de procedencia para centros privados o públicos: encargos, depósitos, compras y donaciones. Estas cuatro posibilidades están directamente relacionadas con las empresas comerciales, mientras que en los centros oficiales solo se contemplan las dos últimas por su especial función conservadora en el proceso documental. En los casos en que se dispone de laboratorios o servicios de reproducción (Archivo General de la Administración, Biblioteca Nacional, Museo del Prado, etc.) se atiende la solicitud del usuario, creando nuevos documentos (duplicados o ficheros digitales) que engrosan otras colecciones. 


\subsection{Centros privados}

Por cuanto respecta a las instituciones privadas, las fotografías se encuentran dispersas en diversos centros, si bien son las agencias y fototecas las que disponen de mayor cantidad. Los objetivos de cada uno de ellos determinan su tratamiento y difusión, por lo que como punto de partida establecemos esta tipología: agencias gráficas, archivos o fototecas, asociaciones, agrupaciones, sociedades, empresas y archivos personales.

Entre estos modelos se establece una clara diferencia por sus objetivos comerciales, es decir, por su intención lucrativa. Las agencias, fototecas y archivos tienen como fin la rentabilidad de sus fondos, mientras que las asociaciones se ocupan primordialmente de la recuperación, conservación y difusión. Algunos proyectos de carácter privado han encontrado apoyo institucional, como el Centre de Fotografia Documental de Barcelona, cuyo objetivo es documentar la vida de esa ciudad en todos sus aspectos, con imágenes captadas por artistas para fomentar la investigación. Fue creado por David Airob, Sonia Balcells, Sandra Balsells, Consuelo Bautista, Cristina Gallego, Jordi Oliver, Carles Ribas, Laura Terré y Joan Tomàs. La propuesta de actuación fue doble: intelectual (reflexión sobre la fotografía) y práctica (agrupación de archivos de los autores más representativos de la ciudad de Barcelona).

Las agencias y fototecas tienen como función primordial ofrecer todo tipo de información en soporte convencional o digital. Para el documentalista gráfico o el ilustrador es imprescindible conocer los objetivos finales, en función de los cuales orientará su trabajo. La relación entre los profesionales y las fototecas se plantea en un doble sentido: como documentalistas internos, tratando el documento para su oferta, o bien externo, en una función entre el autor o empresa y la fototeca, seleccionando el material de acuerdo al proyecto previo. Existen fototecas especializadas que suministran material para obras concretas, según contenidos, aunque generalmente no suelen limitar sus fondos por la lógica repercusión económica. En todo caso establecen normas de actuación que podemos resumir en:

- Gestión administrativa. Registros, peticiones, documentación administrativa, devoluciones, etc.

- Intercambio con centros. Contacto con otras empresas, a modo de depósito, para distribuir fondos, cubrir materias o lagunas.

- Areas documentales. Búsqueda primaria de información en centros oficiales y/o privados para su oferta al usuario.

- Profesionales de la fotografía. Colaboradores especializados en materias concretas (arte, paisaje, biología, medicina, moda, cocina, etc.) a cuyos archivos personales se recurre frecuentemente.

Scire. $11: 1$ (en.-jun. 2005) 159-173. ISSN 1135-3761. 
- Relación con centros técnicos. La realización de duplicados, copias de seguridad o digitalización de los originales implica relación directa con laboratorios de alta calidad.

La consulta de documentos en Internet agiliza la tarea, pero cuando los fondos son cuantiosos se dispone de un doble archivo: originales y reproducciones digitalizadas. Es importante tener en cuenta que no todo está digitalizado y que las grandes fototecas cuelgan en la red solo una parte selectiva de su fondo, por lo que en la búsqueda se hace imprescindible recurrir a los originales (negativos, papel, diapositivas, etc.). Pongamos como ejemplo Aci Press, con 100.000 fotos de cine en línea sobre más de un millón de originales en su fondo. Los documentos digitales se presentan en baja resolución para consulta o envío al usuario, si bien las grandes agencias como EFE, donde el número de temas históricos supera los diez millones de imágenes, permiten la consulta de los originales y una vez seleccionados pasan al laboratorio para escaneado y tratamiento documental.

Son pocas las entidades que se presentan como centros de documentación fotográfica y/o visual, y entre ellas destaca Photo Aleph, que realiza una doble función: exposición y comercialización de imágenes. Se define como una biblioteca de imágenes donde se recopilan, archivan y gestionan toda clase de fotografías y reproducciones artísticas. Realiza exposiciones virtuales que enriquecen progresivamente los fondos y alquila los derechos de reproducción de los mismos para toda clase de medios impresos, audiovisuales e informáticos.

En otro grupo situamos las empresas especializadas cuya función va más allá de los planteamientos normales en el centro de documentación, puesto que realizan el proceso completo según objetivos. Se definen como agencias de gestión y búsqueda de fotografías (y otro tipo de documentos) en archivos institucionales y privados. Citaremos como ejemplo Clam, Edimedia y Dagli Orti (París), Ikona (Roma) y Mary Evans (Londres). En España no es habitual este tipo de empresas, si bien algunas fototecas ofertan este servicio a editoriales: Index, Oronoz y Prisma entre ellas.

Los fondos documentales se dispersan también en archivos y bibliotecas de asociaciones, empresas y colecciones personales, cuya pretensión primera no es la comercialización sino la conservación y difusión. En consecuencia resulta inconveniente identificar lo privado con lo comercial con carácter genérico o excluyente. Los archivos de empresa presentan dos grupos de contenidos: el material generado en sus actividades internas y el adquirido para aplicación y desarrollo de proyectos. La mayoría de las empresas conservan imágenes de sus infraestructuras, recursos, actos comerciales, administrativos o informativos, y otras adquiridas o realizadas para su aplicación a proyectos. Modelo de archivos creados para su aplicación son las empresas informativas y editoriales; en ambos 
casos la reutilización del documento repercute directamente en el ahorro en inversiones y justifica la existencia del archivo.

En cuanto a los archivos personales, tanto de aficionados como de profesionales, la comercialización queda en un segundo plano frente al interés de su recuperación y conservación. El archivo o colección del fotógrafo es un recurso para el documentalista cuando se trata de temas especializados o de proyectos específicos donde se hace imprescindible contar con un profesional. Entre las iniciativas privadas se encuentra la Fototeca Hispalense, proyecto de Miguel Ángel Yáñez Polo para recopilar imágenes de Sevilla desde la invención de la fotografía en 1839. Cuenta con más de cien mil fotos en diversos soportes adquiridas por compra, donación e intercambio, y su función se resume en los siguientes aspectos: investigación sobre la historia de la fotografía en Sevilla, conservación de los fondos antiguos, actualización constante y campo de investigación para estudiosos.

\section{Necesidad del Centro Nacional de Documentación Fotográfica}

La documentación fotográfica constituye una parte esencial de la memoria histórica, a la que los investigadores prestan cada vez mayor atención. La fotografía, si bien ha sido y es uno de los modelos empleados en la ilustración de textos, junto al grabado, la pintura, el dibujo o la infografía, se diferencia de todos ellos por su esencia: el reflejo de la realidad frente a la interpretación. A partir de 1839, año en que la fotografía fue dada a conocer oficialmente en la Academia de París, la imagen representada mediante el nuevo procedimiento químico es la misma que el autor contempla con sus ojos, mientras que el resto son interpretaciones personales de los hechos a partir de un apunte o de una visión.

La revisión de la historia contemporánea desde la fotografía es una asignatura pendiente para los estudiosos. No solo determinadas conductas o situaciones quedan en entredicho o son denunciadas al contemplar las imágenes (accidente mortal de Diana de Gales en París), sino que determinadas fotografías aportan información relevante para el análisis histórico. Por otra parte, la influencia de la imagen fotográfica en la sociedad es cada vez más directa.

Los profesionales de la documentación fotográfica manifiestan y/o denuncian una situación común a la mayoría de los archivos fotográficos españoles con titularidad pública o privada: la necesidad de invertir en la preservación de los fondos documentales que constituyen la memoria gráfica de nuestro país. He aquí un ejemplo: en mayo de 2004 fue protagonista el Museo de Ciencias Naturales, cuyos técnicos valoraron en 62.000 euros la cantidad necesaria para la consolidación y digitalización de las 300 placas de vidrio que tomó Rafael Castro Ordóñez entre 1862 y 1865 durante la expedición española al Pacífico. 
Esta cuestión ha suscitado el debate entre los profesionales de la fotografía y los documentalistas, no solo por el hecho puntual sino por otras cuestiones de superior calado que convergen en la urgente necesidad de la creación de un Centro Nacional de Documentación Fotográfica que aborde cuestiones como las planteadas y, más allá de lo particular, se ocupe de la adquisición, el control, la preservación, la gestión y la difusión de los fondos fotográficos conservados en los centros dependientes de las instituciones estatales.

También la dispersión de los documentos fotográficos, fundamentalmente en archivos, bibliotecas y museos, plantea la necesidad de la creación de un organismo superior con carácter autónomo encargado de la coordinación de los centros de documentación fotográfica, así como la publicación de una guía para profesionales e investigadores con la descripción de los fondos.

Las preguntas se repiten a diario y las respuestas no existen. El paradigma de Laswell exige una intervención inmediata: quién, cómo, dónde, cuándo y por qué. Todas ellas referidas a los fondos, colecciones y conjuntos documentales fotográficos, tan ricos que desbordan a los responsables y, en consecuencia, permanecen en el anonimato. La tarea del centro se concretaría siguiendo los objetivos que indicamos, evidentemente, modificables y ampliables.

Los objetivos generales serían la recuperación del patrimonio fotográfico en colaboración con otras instituciones, la elaboración del censo de centros con fondos fotográficos - estatales, autonómicos y municipales -, la elaboración del catálogo general de contenidos: relación de fondos por centros con descripción de contenidos, el establecimiento de una política de actuación general para todos los centros, el establecimiento de una política de actuación concreta en relación con determinados fondos y la definición de las tipologías documentales.

Los objetivos específicos, por su parte, serían el control del patrimonio fotográfico, la cuantificación de los fondos por centros, la valoración cualitativa, el análisis general de contenidos, la creación de un tesauro general con las temáticas de los fondos, la elaboración de bases de datos para el control de la información, y la gestión y difusión de la información: dossieres, publicaciones, etc.

Del desarrollo de estos objetivos resultarían actuaciones concretas que repercutirían en un mejor funcionamiento de los centros, y especialmente en la comunidad científica, usuario potencial de los fondos y responsable final de la difusión de sus contenidos. En un análisis inmediato, la creación del Centro Nacional de Documentación supondría la coordinación entre centros de documentación de agencias, museos, bibliotecas, fundaciones, etc.; el intercambio de experiencias entre centros; la uniformidad en los criterios de uso de los fondos - normativas de reproducción y publicación, tarifas, etc. - ; la elaboración de informes sobre archivos y colecciones; la gestión de derechos de autor a nivel nacional con 
las instituciones indicadas o con particulares; la gestión de adquisición de fondos privados; la creación del Museo Nacional de Fotografía; la creación de una biblioteca especializada; la creación de una hemeroteca especializada; y la elaboración de un directorio-guía de centros de documentación en España.

\section{Referencias}

Bailac, Montserrat; Catalá, Montserrat (1995). La fototeca. // Fuentes i Pujol, María Eulalia (ed.). Manual de documentación periodística. Madrid: Síntesis, 1995.

Barthes, Roland (1994). La cámara lúcida. Barcelona: Paidós, 1994.

Costa, Joan (1977). El lenguaje fotográfico. Madrid: Ibérico Europea de Ediciones, 1977.

Feininger, Andreas (1977). La nueva técnica fotográfica. Barcelona: Hispano Europea, 1977.

Fontanella, Lee (1992). Los límites de la fotografía documental. // Open Spain. Fotografía Documental Contemporánea en España. Barcelona: Lunwerg, 1992.

Fuentes i Pujol, María Eulalia (ed.) (1995). Manual de documentación periodística. Madrid: Síntesis, 1995.

Miserachs Ribalta, Xavier (1995). Fotógrafo. Barcelona: Grijalbo Mondadori, 1995. 72.

Olivares, Rosa (2003). Cuadros de una exposición. Fragmentos de una colección. // Fondos de la colección de fotografía de la Comunidad de Madrid. Madrid: Consejería de Cultura de la Comunidad, 2003.

Sontag, Susan (1992). Sobre la fotografia. Barcelona: Edhasa, 1992.

Talbot, Henry Fox (1997). El lápiz de la naturaleza. // Archivos de la Fotografía. III: 1 (1997) 31-88.

Trancón Pérez, Santiago (1986). La fotografía arte y documento. // Imágenes para la otra historia. Salamanca: Junta de Castilla y León, 1986.

Valle Gastaminza, Félix del (1990). Las funciones documentales: tipología de centros y servicios de documentación. // José López Yepes (compilador). Fundamentos de información y documentación. Madrid: Eudema, 1990. 